\title{
Performance Analysis of Learning Efficacy of Interactive Foreign Language Teaching under the Network Environment
}

\author{
Zhaoxi Wei \\ General Education Department, Beijing Information Technology College, Beijing, China \\ Email: jgwzx@126.com
}

How to cite this paper: Wei, Z. X. (2019). Performance Analysis of Learning Efficacy of Interactive Foreign Language Teaching under the Network Environment. Open Journal of Modern Linguistics, 9, 395-404. https://doi.org/10.4236/ojml.2019.96032

Received: October 8, 2019

Accepted: November 2, 2019

Published: November 5, 2019

Copyright (อ 2019 by author(s) and Scientific Research Publishing Inc. This work is licensed under the Creative Commons Attribution International License (CC BY 4.0).

http://creativecommons.org/licenses/by/4.0/

\section{(c) (i) Open Access}

\begin{abstract}
With the rapid development of computer technology and network technology, the integration between information technology and teaching promotes the development of interactive teaching under the network environment, which has a great impact on teaching philosophy, teaching method, teaching mode, etc., as well as brings concerns on learning efficacy under network environment to foreign language teaching. Analyzing learning efficacy for interactive teaching under the network environment is of vital significance for implementing the network teaching. Through making the survey of a total of 153 valid undergraduates' questionnaires, and analyzing 153 undergraduates' performance under the interactive network teaching environment via SPSS 17.0, the research shows that cultivating strategies of promoting students' learning efficacy under the network environment should consist of improving network handling capacity, reducing computer anxiety, enriching successful network experience, etc. For foreign language teachers, more attention on students' psychological behavior phenomenon in networking learning will also effectively promote the implementation of interactive foreign language teaching under the network environment.
\end{abstract}

\section{Keywords}

Interactive Teaching, Interactive Foreign Language Teaching, Learning Efficacy, Network Environment

\section{Introduction}

Under the network environment, interaction is playing a vital part in teaching process, and interactive teaching is closely linked with learning process and learning outcome. As the unification between learning process and learning 
outcome, learning efficiency conforms to the educational objective and current national quality-oriented education philosophy as well as stresses the importance of internal psychology and behavior of learners in learning process. To get a better understanding of learning efficacy under the network environment and to effectively promote the implementation of interactive teaching under the network environment, especially the interactive foreign language teaching under the network environment, it is necessary to make a performance analysis of students' learning efficacy under the network environment.

\section{Interpretation of Related Theory and Concept}

\subsection{Interactive Teaching Theory}

Interaction is one of the most fundamental methods of teaching. Interactive teaching idea emerged when the ancient Greek philosopher Socrates and traditional Chinese thinker and educationist Confucius sermoned and educated their students through conversational mode. With the constant development of philosophy, pedagogy, psychology, scholars have obtained more profound understanding of interactive education. In the mid-20th century, American psychologist and educationist Bruner stated the learning method based on psychological theory. He held that the learning process of students is an active knowledge discovery process, and believed that only by participating in cultural interaction can human brain be fully developed. Brown applied the idea of interactive learning into language teaching, systematically expounding the methods of interactive foreign language teaching and proposing corresponding teaching principles. $\mathrm{He}$ stated that interactive learning is that "two or more people work together, exchanging ideas, feelings or thoughts, to influence each other." (Brown, 1994). In fact, he thought that "interaction is the core of communication and is the core of the whole communication." (Brown, 1994). The cycle of any teaching processes must deliver, receive and explain information, and complete the stated teaching task together by discussing and understanding the meaning of language information in a specific context, so as to achieve the teaching goal. However, no matter how complex these processes are, interaction is always a vitally important part in the teaching process.

\subsection{Concept of Learning Efficacy}

At present, there is no uniform standard of the definition of "learning". On the whole, learning is a process in which learners spontaneously build their own cognitive structure. In the aspect of psychology, learning is the continuous change of experience action and thinking. In terms of the definition of the "effectiveness of learning", scholars hold different views. In China, Xiong et al. (2009) define the learning efficiency as: the sum of all learning-related resources which influence learners' learning effect is the effectiveness of learning goal, and learning efficiency is the multifactorial multi-dimensional structure. Yu (2012) holds that learning efficiency refers to the ability of obtaining knowledge, im- 
proving skills and forming thoughts by learners through learning, and is the nature and state of learners' physical and mental harmonious development. She states that learning efficiency is inversely proportional to the working hours and learning time of learners, which is reflected in the learning effect. Jia \& Lu (2014) thinks that learning efficiency is the measure of learning outcome, and learning efficiency, learning effect and learning benefit are the basis of measuring the learning efficiency. In foreign countries, learning efficiency mainly includes learning effect and learning satisfaction, in which the learning effect mainly focuses on the outcome of learning or the obtainment of knowledge and thinking skills.

For quite some time, our country keeps emphasizing the choice and selection towards student assessment, focusing obsessively on result, ignoring the process, and neglecting the development of acquiring knowledge, ability, emotion and value. Development evaluation is to promote students' personality and integrated development, stressing process evaluation, emphasizing the new evaluation methods of improving and reward functions, paying attention to students' needs and evaluating in the process, in addition, students lay emphasis on their subject role, fostering knowledge, technique, thinking ability, innovation awareness and emotion value, as well as their learning, including learning strategy, learning motivation, learning attitude and so on.

Based on learning theory and development evaluation of constructivism, learning efficiency is mainly interpreted from the perspective of learning process and learning outcome (Ardura \& Galán, 2019). Based on the connotation of effectiveness, the learning efficiency is defined as learners' degree of educational objective by using the research on learning efficiency of domestic and foreign scholars. The learning efficiency is interpreted as the following points: learning efficiency is the unification between learning process and learning effect, both of which are the efficiency of learning, and conform to the educational objective and current national quality-oriented education philosophy. The learning efficiency stresses not only the importance of learning effect, but also the internal psychology and behavior of learners in learning process.

\subsection{Linguistics and Interactive Foreign Language Teaching}

The teaching methods of any foreign languages have a guiding effect with linguistic theory, the influence of foreign language teaching theory on foreign language teaching is also applied in the foreign language teaching, and linguistic theory forms a significant branch of applied linguistics. Hence, its key point is "the systematic language teaching and learning based on language acquisition". Interactive foreign language teaching also has a solid language foundation.

1) Dialectical relationship between language and speech and interactive foreign language teaching

Since the publication of Saussure's Course in General Linguistics, the philosophical principle of form and content and universality and particularity have been widely applied in the field of linguistics. As the social and systematic part of 
language, speech has universal motion laws, and as the use of language by individuals, speech is also the shell and form of the language and is restricted by language rules.

In the process of interactive foreign language teaching, language serves as the basis of interaction, and is the specific content of the interaction, without language, the whole teaching process will be meaningless; On the other hand, without words to say, there will be no content in the whole teaching activity. Therefore, language and speech are two dialectically dependent necessary factors in language teaching.

"Managing the relationship between language and speech in a correct manner is the key of foreign language teaching," Wang (2009) said. Traditional foreign language teaching theory is to learn language based on acquiring the language system. Therefore, we have acquired the language system of one language, but we still cannot correctly use it, and our language competence is not good enough. The foreign language teaching theory of constructivism emphasizes the structure of language form, students are able to make sentences which conform to grammatical rules, but these sentences are hard to be applied in real-life foreign language, there is a lack of elasticity in the language which is impacted by the native language. The interactive teaching theory combines the development of language and speech, seemingly providing a perfect answer for the language and speech issue.

2) Linguistic theory of constructivism and interactive foreign language teaching

In the process of interactive foreign language teaching, teachers play a leading role and students play a subject role. During foreign language learning, students construct discourse by their own language knowledge to express thoughts and have information communication with teachers, classmates, computers as well as other external factors. On the other hand, they also construct text for new language materials in environment (including teachers, students, textbooks, computers, etc., and can provide various factors of language information), and construct personal foreign language system to achieve the interactive cycle between language and speech, so as to realize the purpose of mastering a foreign language (Zhang \& Qin, 2014).

3) Cognitive linguistic theory and interactive foreign language teaching

Cognitive linguistics is not only the reflection of brain's outside world by language, but also the results of understanding the outside world. The learning of language knowledge is achieved by the interaction between subjective world and objective world. For example, the establishment of the concept of language category is based on experience and imagination, which is the interaction result between subject and object. The way of classification can be sensory, kinaesthetic, metaphorical or image schema thinking. We cannot obtain the meaning of category through abstract and meaningless symbol operation. The meaning of language is mainly derived from the interaction between human and objective world, from the viewpoint of users to the objective world, it is the result of con- 
ceptual process. As a result, language is not only a thing with form and a set of rules system, but the assistant instrument and means for the interaction between human as the subject and objective world as the object (Saussure, 2001). Language system is dynamic and comes from the language use. Language subsystem has the characteristics of interactivity, hierarchy and timeliness. Grammar changes gradiently, and learning is progressive, existing in specific environment and completed by a specific participant with a clear aim.

\section{Experiment and Analysis}

To get a better understanding of learning efficacy of interactive foreign language teaching under the network environment, a survey of undergraduates' learning efficacy under the network environment is made through the experiment, in which the questionnaire and data statistics methods are mainly adopted. During this experiment, it should be explored: Does the gender, the grade or the major category of undergraduates relate to network environment learning efficacy, if it does, how to affect network environment learning efficacy? Which feeling (ability) affects undergraduates' network learning activity and learning behavior and to which extent?

\section{Survey and Analysis of Undergraduates' Network Environment Efficacy}

1) Analysis of the basic information of questionnaire

In this experiment, random sampling is undergraduates from freshman to senior of X college in Beijing in 2018. A total of 160 questionnaires is distributed, 158 questionnaires are taken back, among which 153 are valid. According to the structure of the samples surveyed, 66 are male, while 87 are female. The number of freshman, sophomore, junior and senior is 30, 49, 54, 20 respectively. And most undergraduates are with personal computers. See Table 1.

Overall, the structure of the samples surveyed is relatively balanced and is suitable for research. According to Table 2, the mean of gender is 1.5686, which is biased towards 2 , indicating that the number of females is greater than that of males. The mean of grade is 2.4183 , which is between $2-3$, indicating that there is a relatively large number of sophomores and juniors. The mean of major category is 1.3922 , which is biased towards 1 , indicating that the major category of samples is scientific technology rather than literature and history. The standard deviation of gender, grade, major category and if you have a personal computer is $.49689, .95017, .50309$ and .22791 , respectively. Grade has the maximum standard deviation, the minimum standard deviation of if you have a personal computer is used to express the difference between variable values, grade has the maximum difference, if there is a computer, there is the minimum difference between the variable values.

2) According to the dimension of different issues, all issues of different dimensions are integrated, and descriptive analysis is conducted on the dimension. 
Table 1. Basic information.

\begin{tabular}{ccccc}
\hline $\begin{array}{c}\text { Basic } \\
\text { information }\end{array}$ & Frequency & Percent (\%) & $\begin{array}{c}\text { Valid } \\
\text { percent }(\%)\end{array}$ & $\begin{array}{c}\text { Cumulative } \\
\text { percent }(\%)\end{array}$ \\
\hline Male & 66 & 43.1 & 43.1 & 43.1 \\
Female & 87 & 56.9 & 56.9 & 100.0 \\
Freshman & 30 & 19.6 & 19.6 & 19.6 \\
Sophomore & 49 & 32.0 & 32.0 & 51.6 \\
Junior & 54 & 35.3 & 35.3 & 86.9 \\
Senior & 20 & 13.1 & 13.1 & 100.0 \\
With personal & 145 & 94.8 & 94.8 & 94.8 \\
computer & & 5.2 & 5.2 & 100.0 \\
Without personal & 8 & & & \\
computer & & 100.0 & 100.0 & \\
Total & 153 & & &
\end{tabular}

Table 2. Statistics.

\begin{tabular}{|c|c|c|c|c|c|}
\hline \multicolumn{2}{|c|}{ Statistics } & \multirow{2}{*}{$\begin{array}{c}\text { Gender } \\
153\end{array}$} & \multirow{2}{*}{$\begin{array}{c}\text { Grade } \\
153\end{array}$} & \multirow{2}{*}{$\begin{array}{c}\text { Major category } \\
153\end{array}$} & \multirow{2}{*}{$\begin{array}{c}\text { If you have a personal } \\
\text { computer }\end{array}$} \\
\hline & Valid & & & & \\
\hline & Missing & 0 & 0 & 0 & 0 \\
\hline \multicolumn{2}{|c|}{ Mean } & 1.5686 & 2.4183 & 1.3922 & .9739 \\
\hline \multicolumn{2}{|c|}{ Median } & 2.0000 & 2.0000 & 1.0000 & 1.0000 \\
\hline \multicolumn{2}{|c|}{ Mode } & 2.00 & 3.00 & 1.00 & 1.00 \\
\hline \multicolumn{2}{|c|}{ Standard deviation } & .49689 & .95017 & .50309 & .22791 \\
\hline & 25 & 1.0000 & 2.0000 & 1.0000 & 1.0000 \\
\hline \multirow[t]{2}{*}{ Percentile } & 50 & 2.0000 & 2.0000 & 1.0000 & 1.0000 \\
\hline & 70 & 2.0000 & 3.0000 & 2.0000 & 1.0000 \\
\hline
\end{tabular}

According to Table 3, the effective value of the four dimensions is 153 . The total score of the feelings of competence, hard work, environment and control is $25,25,30$ and 20 respectively. The minimum of the four dimensions does not reach $50 \%$ of their total scores, indicating that they all have the samples with weak self-efficacy. In maximum, there are samples with complete feelings of competence, environment and control, indicating that there are samples with strong network environment self-efficacy in these three dimensions. In mean, the feeling of competence is 17.7843 , indicating that the overall samples have a good feeling of competence and is confident in obtaining better learning effect in network learning. The mean of the feeling of hard work, environment and control is $16.8301,21.9346$ and 14.2026, respectively. The feeling of environment means undergraduates' feeling in learning network, the highest score suggests their subjective good feeling in network learning environment: stronger feeling of environmental security, better adapted to network learning and using network 
learning environment actively and effectively; In standard deviation, the feeling of control is the weakest, indicating that undergraduates have a weak ability of controlling themselves in network learning activity and learning behavior, and are difficult to prevent themselves from being disturbed by outside world.

3) Tabulating analysis is conducted combined with the difference of the feeling of competence between gender and major category.

According to Table 4, there is a significant difference in the network environment efficacy of undergraduates of different majors. The mean of the feeling of competence and hard work of male undergraduates in science and engineering is 17.92 and 16.95 , respectively, and that of the male undergraduates in literature and history is 18.48 and 17.37 , respectively, showing that the feelings of these male undergraduates are generally similar, but the male undergraduates have slightly Statistical drawing analysis is conducted for the difference between grades and dimensions stronger feelings. Observing the data in Table 4, we can see that the feelings of control and environment of male undergraduates in literature and history are generally similar to that of the male undergraduates in science and engineering, but the latter's feelings of control and environment are slightly stronger. According to Table 5, the female undergraduates in Chinese literature and history have stronger self-efficacy than those in science and technology. Generally speaking, the mean score of the feeling of competence of undergraduates in literature and history is higher than that of the feeling of competence of undergraduates in science and technology.

4) Statistical drawing analysis is conducted for the difference between grades and dimensions.

From the bar chart of grades and dimensions (Chart 1), we can see that there is a significant difference of network environment efficacy between undergraduates of different grades. Among these undergraduates, freshmen have the best feeling of competence, and show the strongest self-efficacy in network environment than other grades, as they are full of ambitions just entering the college campus and there are not many temptations. The four grades all have a good feeling of environment overall, showing that undergraduates have a strong adaptation to the network learning.

Table 3. Descriptive statistics of four dimensions.

\begin{tabular}{cccccc}
\hline & \multicolumn{5}{c}{ Four Dimensions } \\
\cline { 2 - 5 } Descriptive statistics & $\mathrm{N}$ & Minimum & Maximum & Mean & Standard deviation \\
\cline { 2 - 5 } & 153 & 11.00 & 25.00 & 17.7843 & 3.16839 \\
Feeling of competence & 153 & 10.00 & 24.00 & 16.8301 & 3.23181 \\
Feeling of hard work & 153 & 13.00 & 30.00 & 21.9346 & 3.59948 \\
Feeling of environment & 153 & 9.00 & 20.00 & 14.2026 & 2.57355 \\
Feeling of control & 153 & & & &
\end{tabular}


Table 4. Difference between major category and gender male in the feeling of competence.

\begin{tabular}{|c|c|c|c|c|c|c|c|c|c|c|c|c|}
\hline \multirow{3}{*}{$\begin{array}{c}\text { Difference } \\
\text { between major } \\
\text { category and gender } \\
\text { male in the feeling } \\
\text { of competence }\end{array}$} & \multicolumn{12}{|c|}{ major category } \\
\hline & \multicolumn{4}{|c|}{ Science and engineering } & \multicolumn{4}{|c|}{ Literature and history } & \multicolumn{4}{|c|}{ Other categories } \\
\hline & Count & Mean & Maximum & Minimum & Count & Mean & Maximum & Minimum & Count & Mean & Maximum & Minimum \\
\hline $\begin{array}{l}\text { Feeling of } \\
\text { control }\end{array}$ & 38 & 14.34 & 20.00 & 9.00 & 27 & 14.07 & 18.00 & 10.00 & 1 & 13.00 & 13.00 & 13.00 \\
\hline $\begin{array}{c}\text { Feeling of } \\
\text { competence }\end{array}$ & 38 & 17.92 & 25.00 & 11.00 & 27 & 18.48 & 24.00 & 13.00 & 1 & 18.00 & 18.00 & 18.00 \\
\hline $\begin{array}{l}\text { Feeling of } \\
\text { hard work }\end{array}$ & 38 & 16.95 & 24.00 & 10.00 & 27 & 17.37 & 22.00 & 12.00 & 1 & 16.00 & 16.00 & 16.00 \\
\hline $\begin{array}{c}\text { Feeling of } \\
\text { environment }\end{array}$ & 38 & 22.29 & 30.00 & 15.00 & 27 & 22.00 & 28.00 & 17.00 & 1 & 17.00 & 17.00 & 17.00 \\
\hline
\end{tabular}

Table 5. Difference between major category and gender female in the feeling of competence.

\begin{tabular}{|c|c|c|c|c|c|c|c|c|c|c|c|}
\hline \multirow{3}{*}{$\begin{array}{c}\text { Difference } \\
\text { between major } \\
\text { category and gender } \\
\text { female in the feeling } \\
\text { of competence }\end{array}$} & \multicolumn{11}{|c|}{ major category } \\
\hline & \multicolumn{4}{|c|}{ Science and engineering } & \multicolumn{4}{|c|}{ Literature and history } & \multicolumn{3}{|c|}{ Other categories } \\
\hline & Count & Mean & Maximum & Minimum & Count & Mean & Maximum & Minimum & Count & Mean & MaximumMinimum \\
\hline $\begin{array}{l}\text { Feeling of } \\
\text { control }\end{array}$ & 56 & 13.84 & 20.00 & 9.00 & 31 & 14.84 & 20.00 & 10.00 & 0 & & \\
\hline $\begin{array}{c}\text { Feeling of } \\
\text { competence }\end{array}$ & 56 & 17.09 & 25.00 & 11.00 & 31 & 18.26 & 25.00 & 12.00 & 0 & & \\
\hline $\begin{array}{l}\text { Feeling of } \\
\text { hard work }\end{array}$ & 56 & 15.96 & 24.00 & 10.00 & 31 & 17.81 & 24.00 & 12.00 & 0 & & \\
\hline $\begin{array}{c}\text { Feeling of } \\
\text { environment }\end{array}$ & 56 & 21.48 & 30.00 & 13.00 & 31 & 22.42 & 30.00 & 15.00 & 0 & & \\
\hline
\end{tabular}

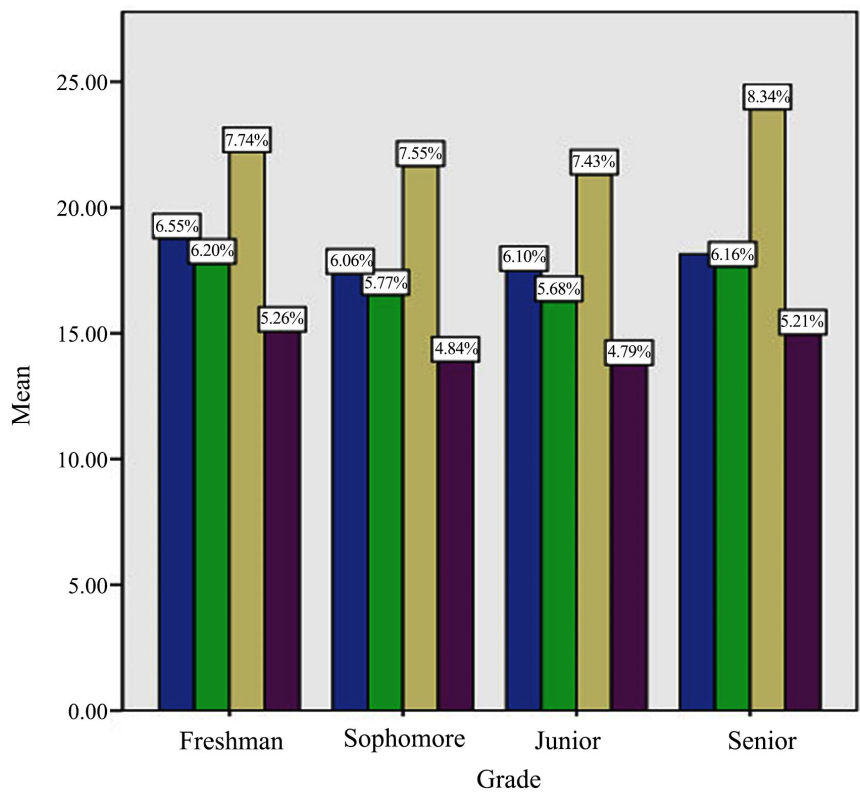

Feeling of competence Feeling of hard work

Chart 1. Analysis of the difference between grades and dimensions. 


\section{Summary of the Survey of Undergraduates' Network Environment Efficacy}

The structure of constructing undergraduates' self-efficacy scale network environment includes four dimensions, network learners' self feeling of competence, self feeling of hard work, self feeling of environmental control and self control of own behaviors (Durak, 2018). Research shows that the personal basic condition of undergraduates has an influence on their self-efficacy in network environment, the network environment self-efficacy level of male undergraduates is higher than that of female undergraduates, the self-efficacy level of undergraduates in literature and history is higher than that of those in science and engineering, and there is a significant positive correlation of hard work between feeling and control level. The cultivating strategies of promoting undergraduates' network environment efficacy consist of improving undergraduates' network handling capacity, reducing computer anxiety, enriching successful network experience, etc, whose validity is verified through experiment.

\section{Conclusion}

With the deepening of research on psychological behavior phenomenon in using network, the research of network learning self-efficacy has drawn increasingly more attention, especially in interactive foreign language teaching under the network environment (Bajorek \& Gawroński, 2018). As the above research shows, the gender, the grade and the major category of learners are related with network environment learning efficacy. Hence, to effectively improve learning efficacy of foreign language teaching, it is necessary to construct a personalized independent network-related learning environment, to create more learning activities that can enhance the information literacy of learners. Besides, the cultivating strategies to promote learners' network efficacy can be adopted, such as enriching successful network experience, strengthening learner's network handling competence and forming the male-together with-female learning community, which will be beneficial for learner's efficacy of interactive foreign language teaching under the network environment.

\section{Conflicts of Interest}

The author declares no conflicts of interest regarding the publication of this paper.

\section{References}

Ardura, D., \& Galán, A. (2019). The Interplay of Learning Approaches and Self-Efficacy in Secondary School Students' Academic Achievement in Science. International Journal of Science Education, 41, 1723-1743. https://doi.org/10.1080/09500693.2019.1638981

Bajorek, K., \& Gawroński, S. (2018). The Use of the Educational Function of Media in Foreign Language Teaching. Social Communication, 4, 48-57.

https://doi.org/10.2478/sc-2018-0006 
Brown, H. D. (1994). Teaching by Principles: Interactive Language Teaching Methodology. New York: Prentice Hall Regents.

Durak, H. Y. (2018). Digital Story Design Activities Used for Teaching Programming Effect on Learning of Programming Concepts, Programming Self-Efficacy, and Participation and Analysis of Student Experiences. Journal of Computer Assisted Learning, 34, 740-752. https://doi.org/10.1111/jcal.12281

Jia, K., \& Lu, H. D. (2014). Learning Efficacy and Its Cultivation. Modern Primary and Secondary Education, 66-69.

Saussure, F. (2001). Course in General Linguistics (Trans. R. Harris). Beijing: Foreign Language Teaching and Research Press.

Wang, D. C. (2009). The Comprehensive Development of Students' Language and Speech. China Languages, $1+108$.

Xiong, J., Dong, N., Lian, R. Y., Wu, J., Xie, W.-L., \& Xu, P. (2009). The Analysis of Efficacy Acting Model of College Students' Bilingual Learning. Journal of Guangzhou University (Natural Science Edition), 5-10.

http://kns.cnki.net/kns/detail/detail.aspx?FilName=GUDZ200906002\&DbName=CJFQ 2009

Yu, M. Y. (2012). Review of Learning Efficacy Research for the Last Decade in China. Journal of Tianjin Academy of Educational Science, 8-11.

Zhang, B., \& Qin, B. (2014). Research on the Multidimensional Interactive Foreign Language Teaching Model Based on the Network Information Technology. In Proceedings of 2014 3rd International Conference on Science and Social Research (pp. 106-109). Paris: Atlantis Press. https://doi.org/10.2991/icssr-14.2014.26 